1708 IMMUNOTOXICOLOGY IN OCCUPATIONAL AND ENVIRONMENTAL CIRCUMSTANCES

${ }^{1}$ Takemi Otsuki ${ }^{*}$, ${ }^{2}$ Claudia Petrarca*. 'Department of Hygiene, Kawasaki Medical School, Kurashiki, Japan; ${ }^{2}$ O.U. Allergy and Immunotoxicology and Occupational Biorepository Centre of Excellence on Ageing (Ce.S.I.) Via Luigi Polacchi, Chieti, Italy

\subsection{6/oemed-2018-ICOHabstracts.137}

Aim of the session To discuss immunotoxicological alterations caused by occupational and envuironmental substances

${ }^{1}$ Dr. Y. Nishimura, ${ }^{2}$ Dr. Q. Niu, ${ }^{3}$ Dr. P. Pedata, ${ }^{4}$ Dr. T. Otsuki

${ }^{1}$ Department of Hygiene, Kawasaki Medical School, Kurashiki, Japan

${ }^{2}$ School of Public Health, Shanxi Medical University, Taiyuan, China

${ }^{3}$ Seconda Università degli Studi di Napoli, DMS-SIMLL, Naples, Italy

${ }^{4}$ Department of Hygiene, Kawasaki Medical School, Kurashiki, Japan

\section{8a SCORES PREDICTIVE FOR ASBESTOS EXPOSURE, MALIGNANT MESOTHELIOMA AND PLEURAL PLAQUE ON THE BASIS OF COMPREHENSIVE IMMUNOLOGICAL ANALYSIS}

\footnotetext{
${ }^{1} \mathrm{Y}$ Nishimura, ${ }^{1} \mathrm{~S}$ Lee, ${ }^{1} \mathrm{H}$ Matsuzaki, ${ }^{1} \mathrm{~N}$ Kumagai-Takei, ${ }^{1} \mathrm{~K}$ Yoshitome, ${ }^{2} \mathrm{~T}$ Nakano, ${ }^{3} \mathrm{~T}$ Kishimoto, ${ }^{1} \mathrm{~T}$ Otsuki. 'Department of Hygiene, Kawasaki Medical School, Kurashiki, Japan; ${ }^{2}$ Department of Respiratory Medicine, Hyogo College of Medicine, Nishimomiya, Japan; ${ }^{3}$ Okayama Rosai Hospital, Okayama, Japan
}

\subsection{6/oemed-2018-ICOHabstracts.138}

Introduction Our findings about immunological profiles resulted from asbestos exposure and related with malignant mesothelioma (MM) allowed us to think a possibility to construct immunological scoring system to screen mesothelioma and asbestos exposure. Therefore, the present study comprehensively investigated immunological characteristics of plasma and peripheral blood mononuclear cells (PBMC) to obtain the formulae of the scores statistically.

Methods Blood specimens were obtained from 27 healthy volunteers (HV), 29 pleural plaque-positive people (PL) and $30 \mathrm{MM}$ patients. Plasma and PBMC were assayed for cytokines and expression of cell surface molecules on $\mathrm{CD}^{+}(\mathrm{Th})$, $\mathrm{CD} 8{ }^{+}(\mathrm{CTL}), \mathrm{CD} 6^{+}(\mathrm{NK})$ lymphocytes and monocytes by luminex and flow cytometry. The part of PBMC was sorted into the four cell populations, which were assayed for mRNAs in fresh or after stimulation by realtime-PCR. The results were examined by multiple regression analysis to obtain the formulae of the scores.

Results Both of MM and PL showed decreases in CXCR3 and NKp46 on T and NK cells respectively and increase in granzyme B mRNA in stimulated CTL. IFN- $\lambda$ and IL-17A in plasma were high in PL, whereas inflammatory cytokines including IL-6 and IP-10 were high in MM. Also, MM showed increase in CTLA-4 on Th cells. The 33 parameters with significant differences were examined by multiple regression analysis. The formulae of scores predictive for MM (Mscore), both of MM and PL meaning asbestos exposure (Ascore) and PL (P-score) were calculated and composed of the three parameters respectively. Every score showed a good ROC curve with sensitivity and specificity near 0.9 .
Conclusion The findings of similarity between PL and MM might reflect alteration caused by inhaled asbestos. The high Treg marker with high inflammatory cytokines might be linked to MM development. Finally, we could obtain the three scores showing good ROC curves, which might be valuable to screen $\mathrm{MM}$ and asbestos exposure.

\section{8b THE IMMUNOTOXICITY AND NEUROTOXICITY OF ALUMINIUM}

Q Niu*, Q Zhang, H Li, L Wang, X Lu. School of Public Health, Shanxi Medical University, Taiyuan, China

\subsection{6/oemed-2018-ICOHabstracts.139}

Aluminium is omnipresent in the world, accounts $8.6 \%$ of the crust, and believed to be a neurotoxicant for a lot of years, and thought to be related with Alzheimer's disease and other neurodegenerative disease. In recent decades, aluminium, as metals, chemical compounds, powders, additives, adjuvants, and nanoparticles have being utilised widely in many fields including human's daily life and industries, and their potential adverse effect on health drew great concern. Aluminium, in the forms of ions, chemical compounds, fine particulate matters, can be ingested, inhaled, or even injected into human body, and translocated into blood stream and immune system to induce immutoxicity, and into central nervous system to induced neurotoxicity. Aluminium may induce neumocytes apoptosis by triggering oxidative stress, and inhibit or activate activity of cytokins, and the immuotoxicity and neurotoxicity induced by aluminium ions and fine aluminium particulate matters was higher than that of relatively large aluminium particles. Besides though blood compartment by which aluminium damage the blood brain barrier, it may enter into central nervous system though olfactory nerve. Aluminium impair behavioural performance of model organisms and rodents. The mechanisms of $\mathrm{Al}$-induced immune and neurotoxicity may be:

- aluminium induces neural cell death by triggering oxidative stress, apoptosis, necroptosis and autophagy through

complicate cell signal transmission pathways;

- promote $A \beta$ deposit,

- promote tau hyperphosphorylation, and together induce neurodegeneration.

- promote cytokine release, trigger inflammation and immune reactions, and

- damage DNA and induce epigenetic changes.

\section{$1708 \mathrm{C}$ EXPOSURE TO SUB-10NM PARTICLES EMITTED FROM A BIODIESEL-FUELED DIESEL ENGINE: IN VITRO TOXICITY AND INFLAMMATORY POTENTIAL}

${ }^{1} \mathrm{~L}$ Malorni, ${ }^{2} \mathrm{~V}$ Guida, ${ }^{3} \mathrm{~A}$ D'Anna, ${ }^{2} \mathrm{G}$ Genovese, ${ }^{4} \mathrm{C}$ Petrarca, ${ }^{2} \mathrm{P}$ Pedata* ${ }^{*} \mathrm{CNR}, \mathrm{ISA}$, Avellino, Italy; ${ }^{2}$ Seconda Università degli Studi di Napoli, DMS-SIMLL, Naples, Italy; ${ }^{3} D I C M A P I$, Università degli Studi di Napoli Federico II, Naples, Italy; ${ }^{4}$ DMSI - Università 'G. D'Annunzio' Chieti-Pescara, Italy

\subsection{6/oemed-2018-ICOHabstracts. 140}

Introduction The inflammatory effects of organic sub-10nm particles generated and emitted from a diesel engine fueled with a biodiesel and a commercial diesel oil are analysed in this paper. Diesel combustion is the major sources of ultrafine 